\title{
Composite materials application on FORMOSAT-5 remote sensing instrument structure
}

\author{
Jen-Chueh Kuo *, Heng-Chuan Hung, Mei-Yi Yang, Chia-Ray Chen, and Jer Lin \\ National Space Organization, HsinChu, Taiwan
}

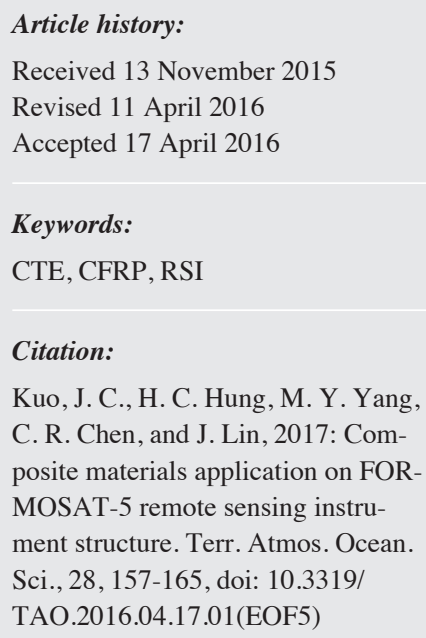

\begin{abstract}
Composite material has been widely applied in space vehicle structures due to its light weight and designed stiffness modulus. Some special mechanical properties that cannot be changed in general metal materials, such as low CTE (coefficient of thermal expansion) and directional material stiffness can be artificially adjusted in composite materials to meet the user's requirements. Space-qualified Carbon Fiber Reinforced Plastic (CFRP) composite materials are applied In the FORMOSAT-5 Remote Sensing (RSI) structure because of its light weight and low CTE characteristics. The RSI structural elements include the primary mirror supporting plate, secondary mirror supporting ring, and supporting frame. These elements are designed, manufactured, and verified using composite materials to meet specifications. The structure manufacturing process, detailed material properties, and CFRP structural element validation methods are introduced in this paper.
\end{abstract}

\section{INTRODUCTION}

The FORMOSAT-5 satellite (FS5) will be operated at $720 \mathrm{~km}$ altitude with 98.28 degree inclination angle in a sun synchronous orbit. An Optical Remote Sensing Instrument, with $2 \mathrm{~m}$ resolution of panchromatic (PAN) image and $4 \mathrm{~m}$ resolution of multi-spectral (MS) image capabilities, is the primary FS5 payload. In order to assemble the optical components with the assistance of the Aerospace Industrial Development Corporation (AIDC) in engineering drawings, structural manufacturing, and structural assembly, the RSI structural model (SM) was successfully completed on December of 2012. The National Chung-Shan Institute of Science \& Technology (NCSIST) also helped with their research know-how on composite material tube development.

The telescope is the main FS5 RSI subsystem. In addition to the structure, the telescope consists of CMOS type Focal Plane Assembly (FPA) and optical components. Moreover, the RSI structure needs to be designed as a strong and stable platform to ensure that FPA as well as the optical components [including the primary mirror (M1), secondary mirror (M2), and correct lenses assembly] will survive the

\footnotetext{
* Corresponding author

E-mail:kuo@nspo.narl.org.tw
}

launch environment and that high precision images can be taken from orbit.

From Hung (2010), the RSI structure is composed of the Main Plate, M2 Support Ring, M2 Strut Frame, Main Plate Support Frame, and Top Plate. The Main Plate, M2 Support Ring, and Top Panel are made of Carbon Fiber Reinforced Plastic (CFRP) honeycomb panel face sheet with aluminium core. The M2 Strut Frame and Main Plate Support Frame are assembled with CFRP tube. The Main Plate design purpose is to support the primary mirror, Correct Lens Assembly and FPA. The secondary mirror, M2 Support Bracket, M2 Spider, and M2 Baffle are supported by the M2 Support Ring, which is connected to the Top Panel by the M2 Support Ring Supporter. The Main Plate Support Frame supports the main plate and connected to the Top Panel. The M2 Strut Frame consists of six struts and interface brackets connecting the M2 Support Ring to the Main Plate. The Top Panel is on the bottom of the Telescope, connected to the satellite bus by top supports. The RSI Cover Assembly is installed directly to the Top Panel and covered by a thermal blanket to maintain the required thermal environment. The overall RSI configuration is shown in Fig. 1. 


\section{RSI STRUCTURE MAJOR MATERIAL PROPERTIES}

There are three primary materials used in the RSI structure: CFRP material, honeycomb plate core material, and adhesive bonding material. According to Yang (2009), the properties of these materials are described in sections 2.1 to 2.3 .

\subsection{CFRP Material}

With the advantages of low CTE design and high stiffness, the $350^{\circ} \mathrm{F}$ cured $954-3$ cyanate resin with high modulus of M55J carbon fibre was selected for honeycomb plate face sheet materials for the Main Plate, M2 Support Ring, and Top Panel. Compared with other CFRP materials, M55J/954-3 possesses lower moisture absorption property, which provides a more stable environment from the ground into space. From the analysis prediction, the orientation angle of each ply can be determined and applied in the manufacturing process. According to Yang (2009), the unit-directional M55J/954-3 material properties are listed in Table 1.

\subsection{Honeycomb Core Material}

The honeycomb plate core design purpose is to provide enough stiffness and bending moment resistance for the overall structural system. The local honeycomb panel stresses can be largely affected by the core density. The aluminium core selection needs to be carefully analysed. According to the structural predictions from the preliminary design to critical design phase, the honeycomb core type used in the Main Plate, M2 Support Ring, and Top Panel, is designed to be 5056 alloy of 1/8-5056-0.002P hexagonal aluminum honeycomb. The honeycomb core material properties are listed in Table 2 (Hexcel 1999).

\subsection{Adhesive Bonding Material}

There are several different adhesive bonding materials used in the RSI structure on different areas and bonding conditions. Redux 312 film bonding between the honeycomb panel face sheet and aluminium core is cured in an autoclave. FM410 adhesive glue is generally used to fill the cavities between the honeycomb and fitting and needs to be cured in an autoclave with the honeycomb panel. However, EA9341 adhesive glue is selected for the Top Panel fitting and is bonded at room temperature. The EA9341 application is described in section 3.4. The detailed bonding process and verification results will be described in the following sections.

\section{MAIN RSI STRUCTURE ELEMENT DESCRIPTION}

\subsection{Main Plate}

As shown in Figs. 1 and 2 the Main Plate supports the

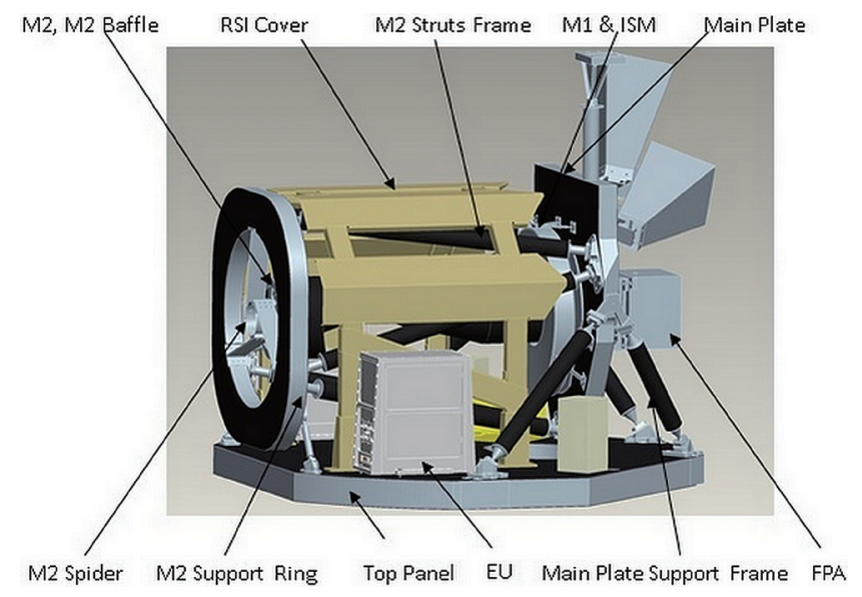

Fig. 1. FS5 RSI configuration. (Color online only)

Table 1. The material properties of unit-directional M55J/954-3.

\begin{tabular}{cc}
\hline Type & UD \\
\hline UD & M55J/954-3 \\
Manufacturer & Hexcel \\
Density $\left(\mathrm{g} \mathrm{cm}^{-3}\right)$ & 1.622 \\
$0^{\circ}$ Tensile Modulus (E1) GPa & 324 \\
$90^{\circ}$ Tensile Modulus (E2) GPa & 6.2 \\
In-plane Shear Modulus (G12) GPa & 3.9 \\
Poisson's Ratio v12 & 0.28 \\
$0^{\circ}$ Tensile Strength (Xt) MPa & 2303 \\
$0^{\circ}$ Comp. Strength (Xc) MPa & 951 \\
$90^{\circ}$ Tensile Strength (Yt) MPa & 35 \\
$90^{\circ}$ Comp. Strength (Yc) MPa & 50 \\
Interlaminar shear strength (ILSS) MPa & 80 \\
$0^{\circ} \mathrm{CTE}\left(\right.$ ppm ${ }^{\circ} \mathrm{C}^{-1}$ ) & -0.63 \\
$90^{\circ} \mathrm{CTE}\left(\mathrm{ppm}{ }^{\circ} \mathrm{C}^{-1}\right.$ ) & 22.4 \\
\hline
\end{tabular}

Table 2. The material properties of 5056 alloy of 1/8-5056-0.002P hexagonal aluminum honeycomb.

\begin{tabular}{cc}
\hline Type & UD \\
\hline Specification & MIL-C-7438 \\
Manufacturer & Hexcel \\
Form & Honeycomb \\
Density $\left(K g ~ \mathrm{~mm}^{-3}\right)$ & $1.3 \mathrm{E}-3$ \\
Compressive modulus $(\mathrm{E} 3) \mathrm{GPa}$ & 3.9 \\
Plate Shear Modulus in L Direction $\left(\mathrm{G}_{\mathrm{L}}\right), \mathrm{MPa}$ & 985 \\
Plate Shear Modulus in G Direction $\left(\mathrm{G}_{\mathrm{W}}\right), \mathrm{MPa}$ & 351 \\
Compressive Strength, Ultimate $\left(\mathrm{F}_{\mathrm{cu}}\right), \mathrm{Mpa}$ & 8.96 \\
Shear Strength in L Direction, Ultimate $\left(\mathrm{Fsu}_{\mathrm{L}}\right), \mathrm{MPa}$ & 5.10 \\
Shear Strength in W Direction, Ultimate $\left(\mathrm{Fsu}_{\mathrm{W}}\right), \mathrm{MPa}$ & 3.03 \\
\hline
\end{tabular}




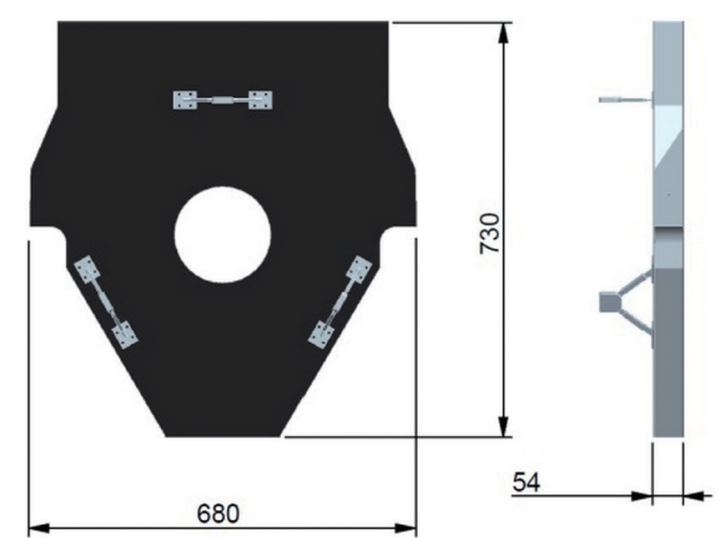

Fig. 2. Main plate configuration (unit: $\mathrm{mm}$ ). (Color online only)

primary mirror, FPA, Correct Lens Assembly, M1 Baffle, and Star Cameras. The Main Plate together with the M2 Support Ring assembly provides a stiff platform for the telescope assembly. Furthermore, the Main Plate is mounted onto the Top Panel by the Main Plate Support Frame, which is the main load path to the satellite bus. The Main Plate is a honeycomb panel composed of CFRP face sheet as well as an aluminium core. The fibre ply orientation and layup sequence for the CFRP face sheet is designed as $\left[0^{\circ}{ }_{2} / \pm 45^{\circ}{ }_{2} / 90^{\circ}{ }_{2}\right]_{\mathrm{S}}$ of M55J/954-3 material. The thickness of each ply is $0.125 \mathrm{~mm}$. The aluminium core is made of 5056 alloy of 1/8-5056-0.002P hexagonal aluminum honeycomb with $50 \mathrm{~mm}$ thickness.

\subsection{M2 Support Ring}

Figure 3 shows the M2 Support Ring mounted onto the Top Panel by ring supporters and connected to the Main Plate by the M2 Struts Frame. Three (3) M2 Spiders are installed in the inner side of the M2 Support Ring to support the M2 bracket. The M2 bracket is the interface between the M2 Baffle and M2 Fitting. The secondary mirror is then mounted to the M2 Fitting. The M2 Support Ring is a ring shaped sandwich panel made of CFRP face sheet with an aluminium core. The M2 Support Ring face sheet material is $\left[0^{\circ}{ }_{2} \pm 45^{\circ}{ }_{2} / 90^{\circ}{ }_{2}\right]_{\mathrm{S}}$ ply orientation with M55J/954-3 prepared material, and 5056 alloy of 1/8-5056-0.002P hexagonal aluminum honeycomb material is used for the core material.

Before these two sandwich panels are cured in the autoclave, Redux 312 film is paved between the face sheet and core, with FM410 adhesive glue inserted between the titanium fittings and honeycomb core. This fitting installation process is called a hot bonding process. After curing in the autoclave, the sandwich panel is machined to the designed configurations and the inserts are potted into the panel with EA9394 adhesive glue. The Main Plate and M2 Support Ring honeycomb panel manufacturing process is illustrated in Fig. 4.

\subsection{Main Plate Support Frame and M2 Struts Frame}

The Main Plate Support Frame is the mechanical interface for the telescope structure and Top Panel. This frame supports the Main Plate at two edge interfaces, left and right hand sides, and is made of CFRP tubes with glued INVAR material end fittings and angle brackets at the Main Plate interface. The Main Plate Support Frame is mounted onto the Top Panel. This configuration is shown in Fig. 5. There are two INVAR material supporters to support the M2 Support Ring due to RSI stiffness considerations.

There are six (6) CFRP tubes that compose the M2 Struts Frame. Each tube is equipped with two titanium interface fittings on both ends. There are twelve (12) interface fittings in the M2 Struts Frame. This frame is mounted onto the Main Plate with three (3) interface fittings and M2 Support Ring supports through three (3) interface brackets. The M2 Struts Frame configuration is shown in Fig. 6.

Both the Main Plate Support Frame and M2 Struts Frame are assembled in M55J/954-3 prepared uni-directional (UD) layer made tubes with $\left[ \pm 35^{\circ} / 0^{\circ}{ }_{6} / \pm 35^{\circ} / 0^{\circ}{ }_{6}\right.$ s ply orientation. During manufacturing the needed prepared UD layer is cut to the designed dimensions according to the ply orientation. When all UD layers are well prepared, each layer is rolled around a tube tooling fixture with the designed directional layup sequence. Once all of the layers are completely stacked, the model is placed into the autoclave for curing. The UD prepared lay-up process follows HSP-L3 specifications and curing cycle for the HSP-C2-M2 specification. When the cured CFRP tubes are taken from the autoclave, all of the tubes are demoulded and cut to the designed lengths. The final CFRP tube model is shown in Fig. 7.

\subsection{Top Panel}

The main purpose of the Top Panel is to provide mechanical support for RSI components. The Top Panel is connected with the FS5 bus structure by ten (10) top supporters because the top supporters are designed to absorb thermal deformations coming from the satellite bus. The Top Panel configuration is shown in Fig. 8. The final model is shown in Fig. 9.

The Top Panel is a honeycomb plate with its face sheet made of UD prepared M55J/954-3 material layers with $\left[0^{\circ} / 36^{\circ} / 72^{\circ} /-72^{\circ} /-36^{\circ}\right]_{\mathrm{S}}$ ply orientation. The top panel aluminium core is made of 5056 alloy of 1/8-5056-0.002P hexagonal aluminum honeycomb material with $62.5 \mathrm{~mm}$ thickness. The Top Panel is manufactured by Xperion Aerospace $\mathrm{GmbH}$, one German structure manufacturer. In order to control the Top Panel surface flatness, a Cold Bonding process is used to install the fittings. This means that titanium fittings are mounted into the honeycomb panel with EA9341 adhesive glue and cured at room temperature. The Top Panel manufacturing process is illustrated in Beller and Phofl (2012) Fig. 10. 


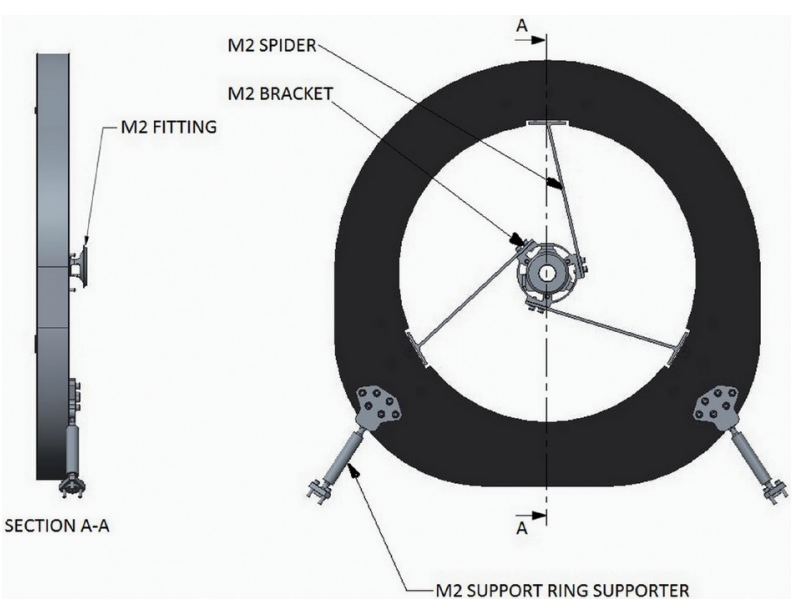

Fig. 3. M2 support ring configuration. (Color online only)
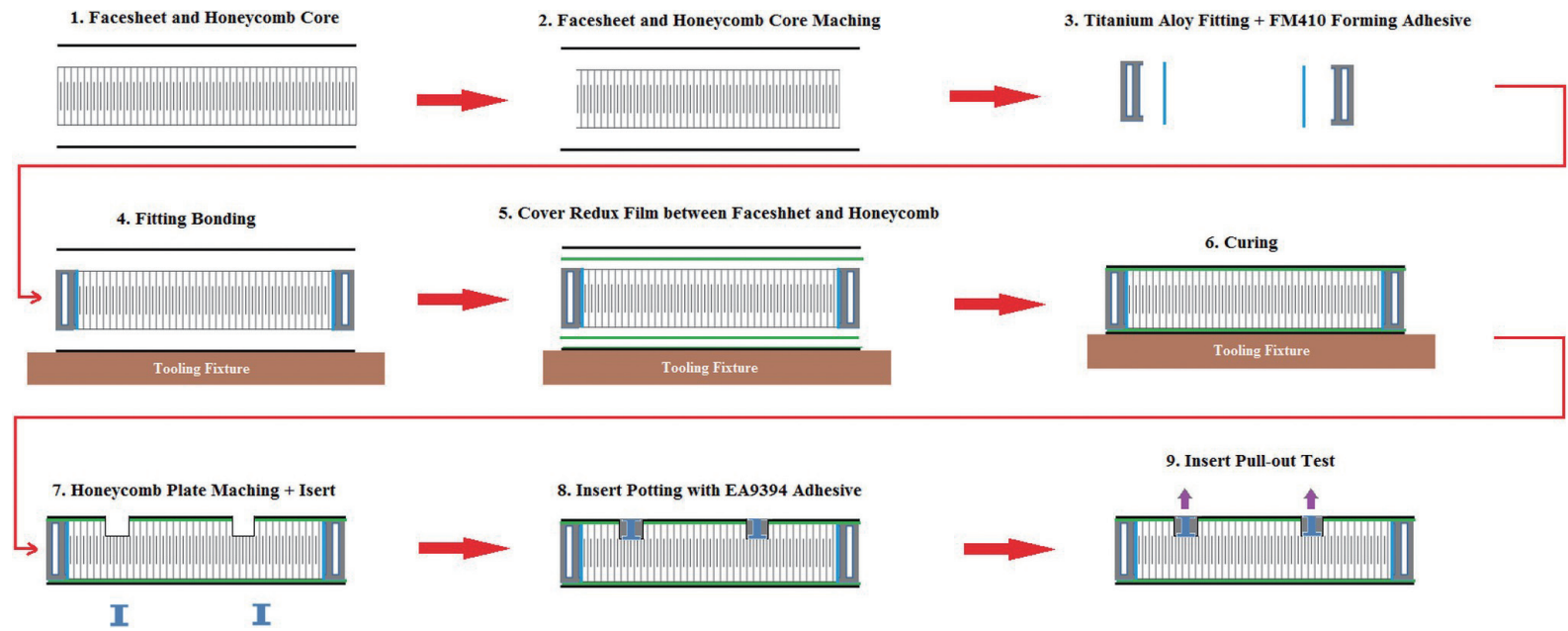

Fig. 4. Main plate and M2 support ring manufacturing illustration process. (Color online only)

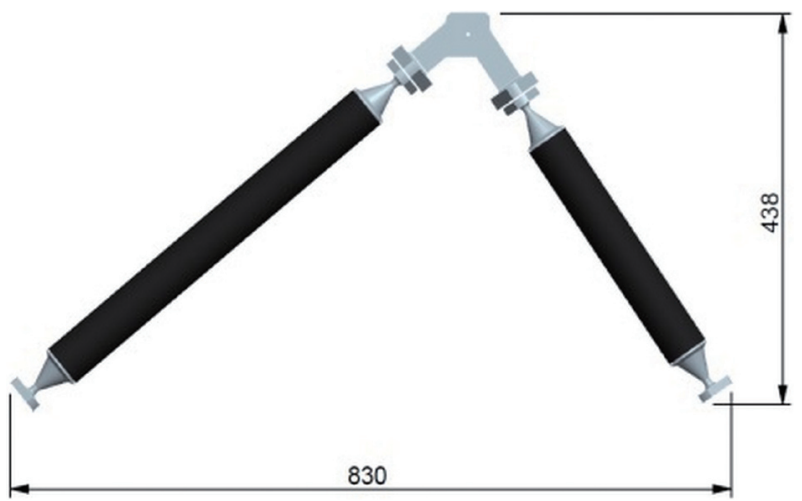

Fig. 5. Main plate support frame configuration. (Color online only)

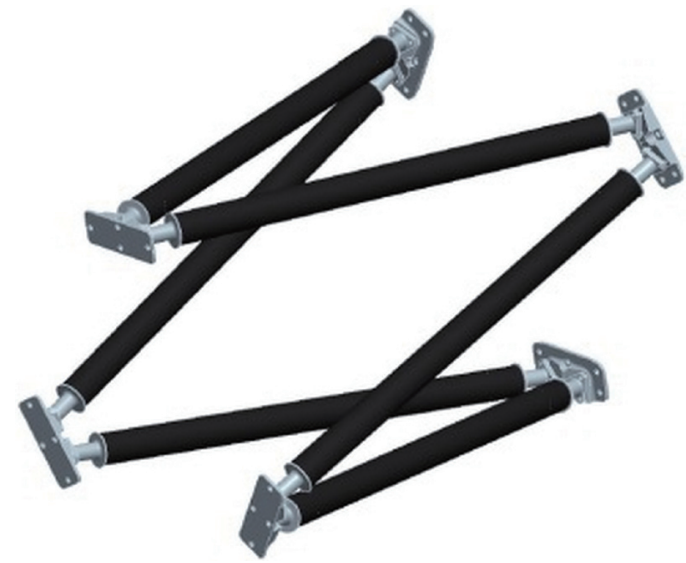

Fig. 6. M2 struts frame configuration. (Color online only) 

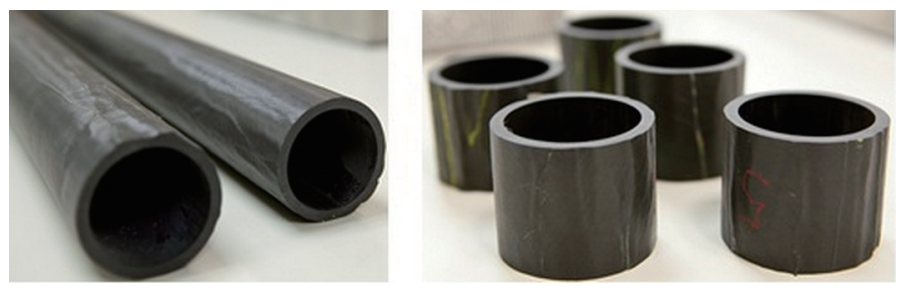

Fig. 7. CFRP completed tube (left) and test cutting tubes (right). (Color online only)
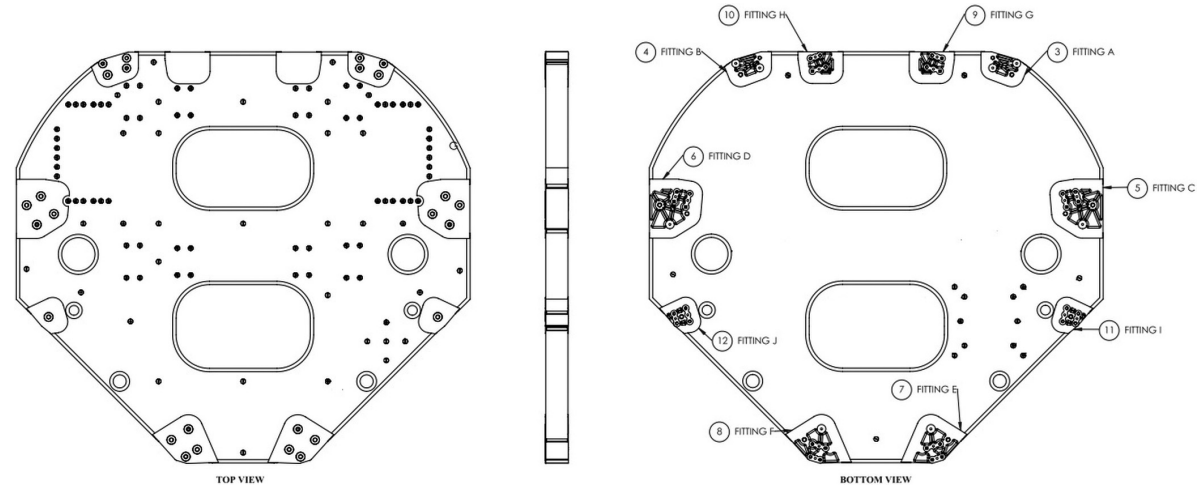

Fig. 8. Top panel configuration.

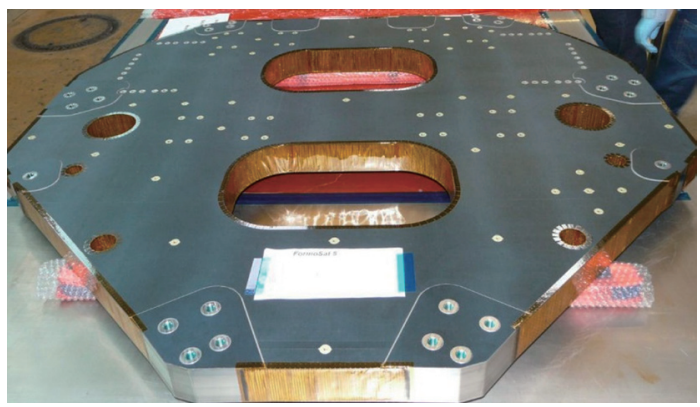

Fig. 9. Top panel final model. (Color online only)

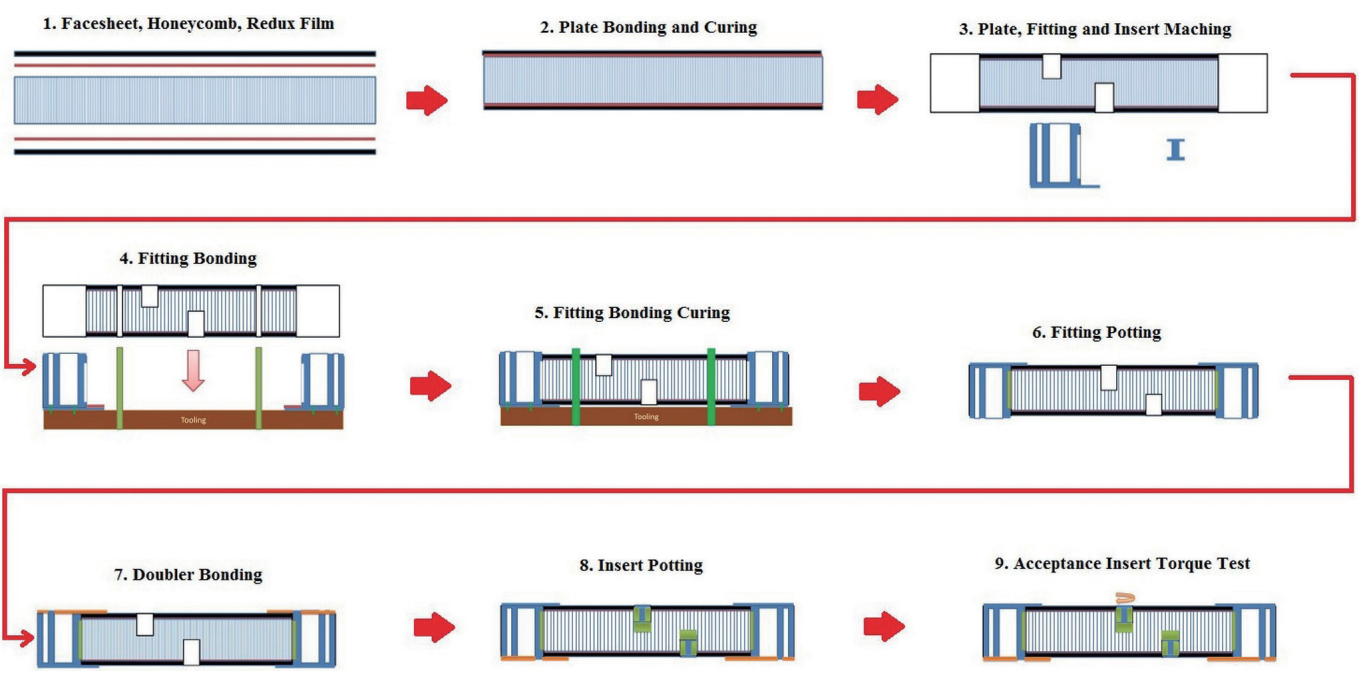

Fig. 10. Top panel manufacturing illustration process. (Color online only) 


\section{RSI STRUCTURE MODEL ASSEMBLY AND VERIFICATION}

\subsection{Structure Elements Validation}

Several RSI structure verification types are applied from the structural elements to the RSI structure model assembly. For the CFRP honeycomb panels (including the Main Plate, M2 Support Ring, and Top Panel), the validation includes panel flatness measurement, honeycomb panel coupon lap shear test, flatwise tensile test, 4-point bending test, X-ray check, and panel insert pull-out test. For the CFRP layup tube, there are the fiber volume check, tube radial crushing test, Optical Microscope (OM) check, bonding test, and tensile test. From the verification results, all test criteria are accepted for both the CFRP honeycomb panel and CFRP layup tube. Table 3 summarizes the RSI structure major verification types and their criteria.

The most critical test is the tube OM check because it can detect whether the CFRP tubes are normally cured or not. From section 3.3, these tubes are made of prepared UD material with $30 \%$ resin content. These resins shall be retained as much as possible during tube curing process. If the resin is overflown during the curing process, it could result in fibre cracks. The tube edge cracks on trial run tubes are shown in Figs. 11 and 12. From Chen (2011a, b), the critical tube manufacturing process that avoids fibre cracks seals the tube ending with vacuum sealant tape, which prevents resin overflow from the tube end. In order to meet the design requirements, an average resin content of $25.8 \%$ was verified to effectively avoid fibre cracks. The final CFRP tube integrity was successfully proven by passing the $\mathrm{OM}$ check, as shown in Fig. 13.

\subsection{RSI Structure Model Assembly}

Before mounting the FPA and optical components, the RSI structure model is assembled with dummy components and verified using the quasi-static load test. The dummy M1 is first mounted to the Main Plate with Iso-Static Mounting (ISM). Because this mounting process will be followed for flight component installation, this mounting process is carefully proceeded to control the overall flatness of the ISM mounting positions. If the ISM is not well mounted, the extra load could make the ISM yield and the M1 could be seriously distorted, impacting the image quality. At the same time the dummy M2, M2 bracket and spider are assembled with the M2 Support Ring in another fixture. When the preliminary Main Plate and M2 Support Ring assembly are finished, they are installed to the RSI installation fixture for final assembly. In the final assembly stage, the Main Plate Support Frame and M2 Struts Frame are connected with the dummy top panel. During installation, aluminum washers are used in some connection joints to adjust the telescope orientation before being bolted with the final torque. When all structural elements are completely assembled, Coordinate Measuring Machines (CMM) are used to ensure that all controlled dimensions are within specifications. The major RSI Assembly process is illustrated in Fig. 14.

\subsection{RSI Structure Model Vibration Test Verification}

After the RSI structure model is completely assembled, the quasi-static load test and minimum workmanship random vibration test are performed (Kuo 2009). The primary purpose of the quasi-static load test is to verify the RSI structure member strength using the sine burst vibration test. Following that, the minimum workmanship level random vibration test is performed to detect any material, process or workmanship defects. For the quasi-static load test, the test level is defined as 1.25 times the coupled load analysis result, which means that the RSI axial ( $\mathrm{Z}$ direction) load is $13.6 \mathrm{~g}$ and lateral ( $\mathrm{X}$ and $\mathrm{Y}$ directions) loads are 8.1 g. The test configurations are presented in Fig. 15 for the $X$, $\mathrm{Y}$, and $\mathrm{Z}$ directions, respectively. From the test results, RSI integrity is well maintained under severe dynamic environments

In order to realize star camera effect on the RSI dynamic characteristics, the sinusoidal signal sweep search was performed twice, once with star camera dummies and once without star camera dummies. The results show that $12 \mathrm{~Hz}$ difference was produced in RSI in the first X and Z direction modes, but only $2 \mathrm{~Hz}$ difference in RSI in the first $\mathrm{Y}$ direction mode. This large mode difference in the $\mathrm{X}$ and $\mathrm{Z}$ directions is due to the large centre of gravity offset coming from the star cameras. This information is valuable when mounting flight star cameras and performing the satellite vibration test.

In order to make the RSI optical instrument structure more stable, the micro-setting vibration test was performed by exposing the RSI Flight Model to one-fourth the minimum workmanship level input from $20-2000 \mathrm{~Hz}$ for $60 \mathrm{sec}$ in three orthogonal axes, respectively. From the pre/post sinusoidal sweep vibration test response comparisons, the micro-setting test is effective for FORMOSAT-5 RSI structure stability. The optical performance measurements indeed provide useful information to confirm structural integrity.

\subsection{Moisture Desorption Effect on RSI Flight Model}

The vacuum induced dry out effect in composite structures is another possible issue that could impact optical images. Thus, the moisture desorption effect in M55J/954-3 material needs to be validated in order to analyse the defocusing effect between M1 and M2. To predict the moisture release deformation of composite materials, the coefficient of moisture expansion (CME) and maximum moisture content of M55J/954-3 need to be determined using moisture absorption/desorption tests (ASTM 2004). Once this information is 
obtained the numerical hygro-mechanical RSI finite element model (RSI FEM, shown in Fig. 16) can be created and the defocusing variation obtained. From Yang $(2013,2014)$, the CME values of M55J/954-3 material tube are calculated using the classical laminate theory. Point zero eighty-two per cent of the maximum moisture content can be measured on the M55J/954-3 UD flat sample and set as the environmental control value during RSI flight model assembly, alignment and calibration. According to the numerical prediction from RSI FEM, if the RSI structure humidity environment is well controlled to prevent additional moisture absorption after the RSI is baked out, $0.9 \sim-1.3 \mu \mathrm{m}$ defocusing variation can be maintained from the ground to orbit and that defocusing variation is acceptable in an optical image.

The moisture variation history plot for as-run CFRP test tube samples is shown in Fig. 17 and it shows that the

Table 3. RSI structure major verification methods.

\begin{tabular}{|c|c|c|c|c|c|c|c|}
\hline & $\begin{array}{c}\text { CFRP } \\
\text { Facesheet }\end{array}$ & $\begin{array}{l}\text { Honeycomb } \\
\text { Core }\end{array}$ & $\begin{array}{c}\text { Panel } \\
\text { Fitting }\end{array}$ & Insert & $\begin{array}{l}\text { CFRP } \\
\text { Tube }\end{array}$ & $\begin{array}{c}\text { Tube } \\
\text { Fitting }\end{array}$ & Remarks \\
\hline Flatness (Finished Plate) & $\sqrt{ }$ & & & & & & Overall Flatness $\leq 0.8 \mathrm{~mm}$ \\
\hline Lap Shear Test - 1 (Coupons) & $\sqrt{ }$ & & $\sqrt{ }$ & & & & Minimum Strength $=15.5 \mathrm{Mpa}$ \\
\hline Lap Shear Test - 2 (Coupons) & $\sqrt{ }$ & $\sqrt{ }$ & & & & & Minimum Strength $=5.12 \mathrm{Mpa}$ \\
\hline Flatwise Tensile Test (Coupons) & $\sqrt{ }$ & $\sqrt{ }$ & & & & & Minimum 650 psi or $100 \%$ core failure \\
\hline Pure Bending Test (Coupons) & $\sqrt{ }$ & $\sqrt{ }$ & & & & & Smallest Failure Load: 24134 N \\
\hline X-Ray Check (Finished Plate) & & & $\sqrt{ }$ & $\sqrt{ }$ & & & $\begin{array}{l}\text { M4: } 3.1 \mathrm{Nm} \\
\text { M5: } 5.5 \mathrm{Nm} \\
\text { M5: } 5.5 \mathrm{Nm}\end{array}$ \\
\hline Insert Pull-Out Test (Finished Plate) & & $\sqrt{ }$ & & $\sqrt{ }$ & & & Record Ultimate Strength Load \\
\hline Ultra-sonic inspection (Finished Plate) & $\sqrt{ }$ & $\sqrt{ }$ & & & & & $\begin{array}{l}\text { No defects greater than a } 5 \mathrm{~mm} \text { diameter } \\
\text { circle }\end{array}$ \\
\hline Optical Microscope Check (Coupons) & & & & & $\sqrt{ }$ & & 100x and 50x images \\
\hline Radial Crushing Test (Coupons) & & & & & $\sqrt{ }$ & & $\begin{array}{l}\text { Applied Load } \geq 30 \mathrm{~N} \mathrm{~mm}^{-1} \text {, test on the } \\
\text { height direction of tube }\end{array}$ \\
\hline Fiber volume $(\%)$ & & & & & $\sqrt{ }$ & & $58-62 \%$ \\
\hline $\begin{array}{c}\text { Tube Bonding Tensile Test (Finished } \\
\text { Tube) }\end{array}$ & & & & & $\sqrt{ }$ & $\sqrt{ }$ & $18000 \mathrm{~N}$ for $5 \mathrm{~min}$ \\
\hline $\begin{array}{c}\text { Quasi-Static Test (RSI Structure } \\
\text { Model) }\end{array}$ & & & & & & & $\begin{array}{l}\text { Axial: } 13.6 \mathrm{~g} \\
\text { Lateral : } 8.1 \mathrm{~g}\end{array}$ \\
\hline
\end{tabular}
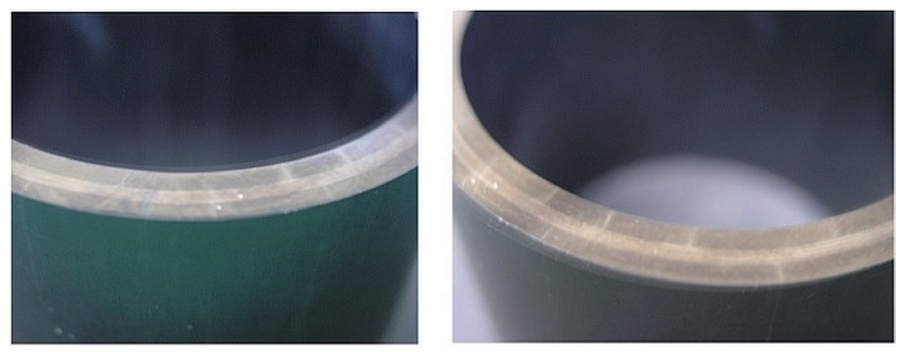

Fig. 11. Cracks in the end-edge of cured CFRP tube. (Color online only)
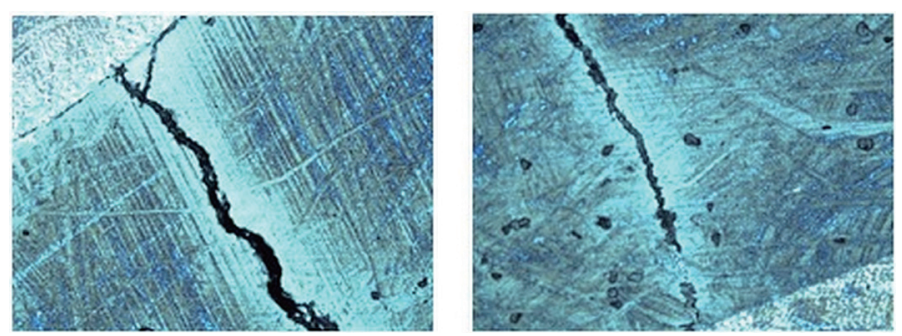

Fig. 12. CFRP tube crack (50x images). (Color online only) 


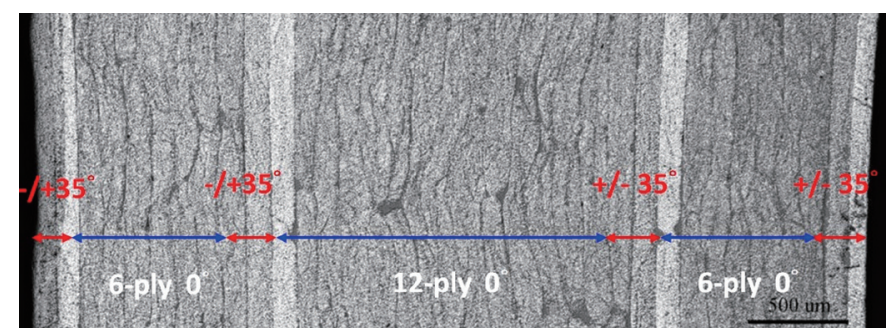

Fig. 13. CFRP tube on 100x image. (Color online only)

1. Main Plate Assembly
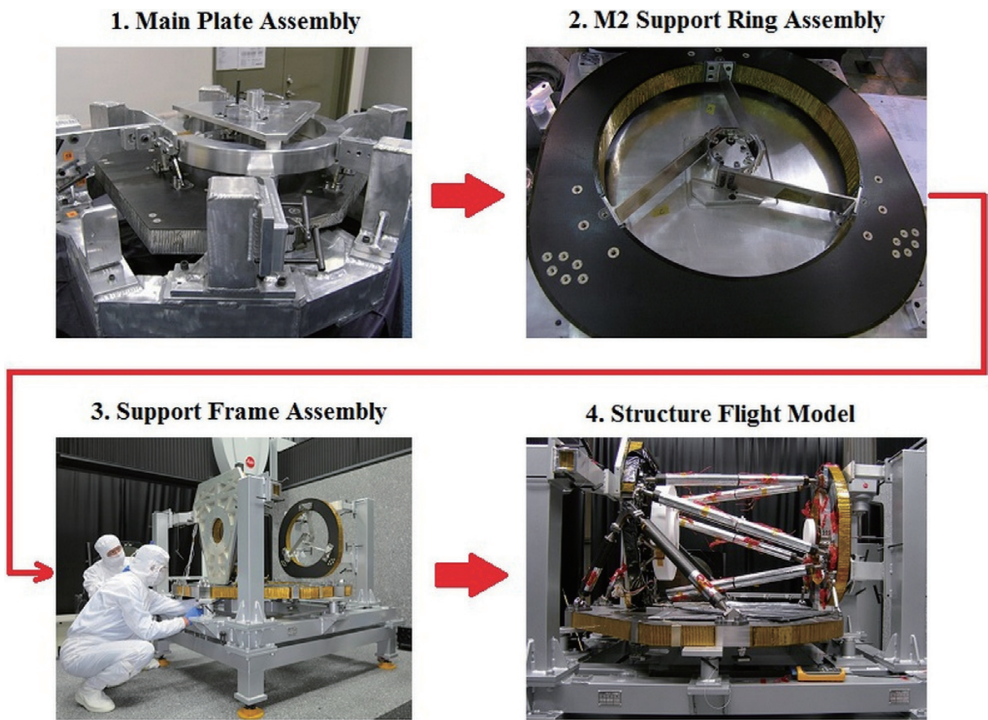

Fig. 14. RSI structure model assembly process. (Color online only)
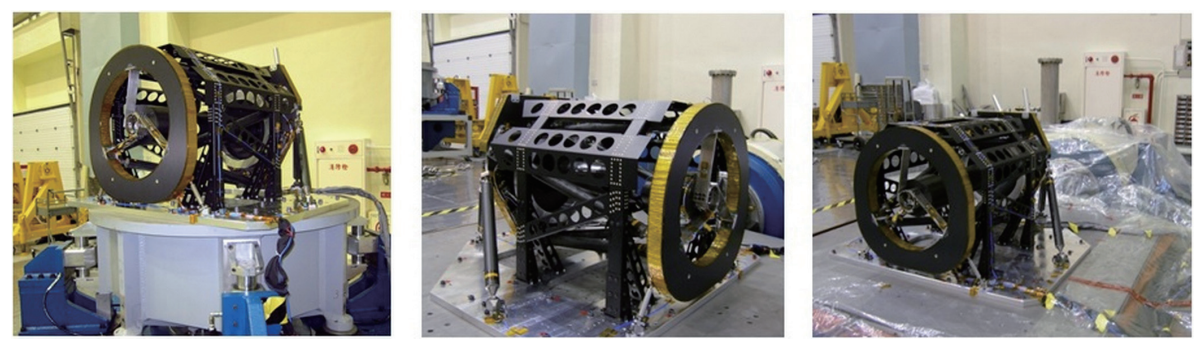

Fig. 15. RSI structure model test configuration (left: $\mathrm{X}$ axis test, middle: $\mathrm{Y}$ axis test, right: $\mathrm{Z}$ axis test). (Color online only)

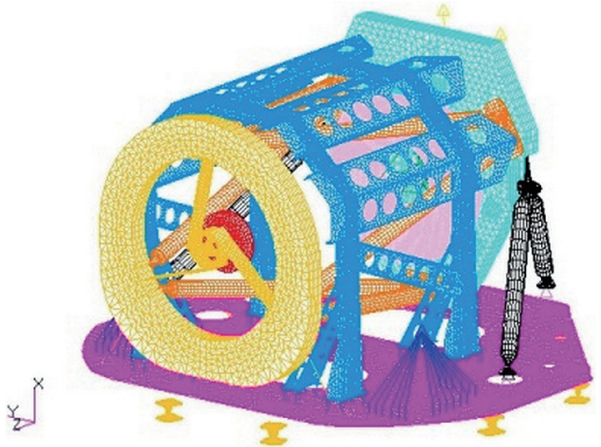

Fig. 16. RSI hygro-mechanical FEM. (Color online only) 


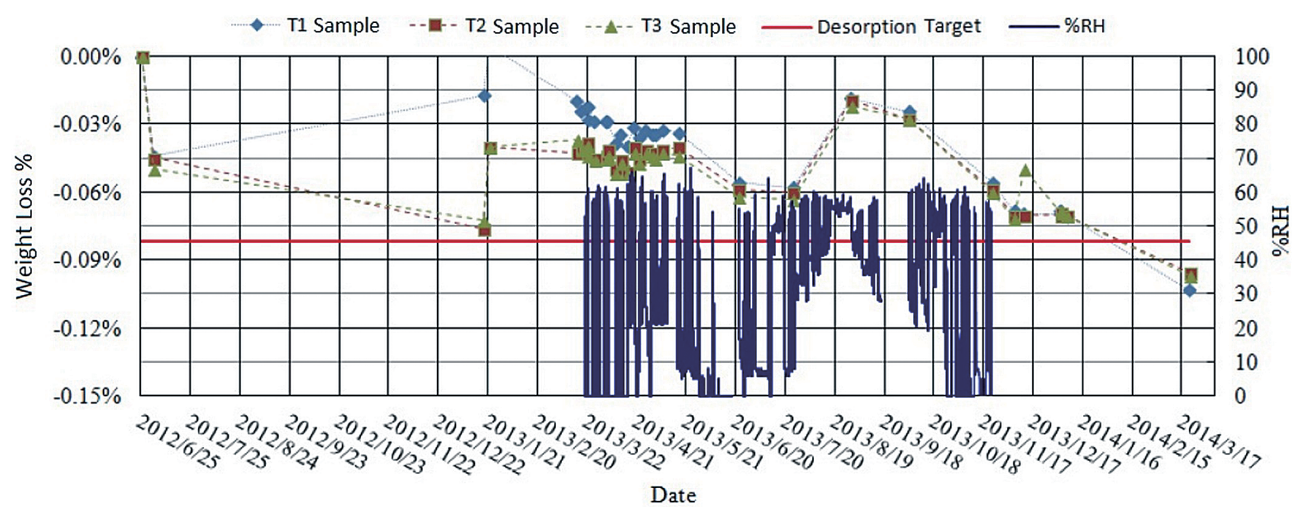

Fig. 17. The moisture content variation plot for RSI as-run CFRP test samples. (Color online only)

environment humidity condition for the FS5 RSI flight model are well controlled during different development phases.

\section{CONCLUSION}

From different verification types, it can be shown that CFRP materials were successfully applied in the FORMOSAT-5 RSI structure. There are many advantages for this application on RSI structures, including light weight, higher stiffness, designed CTE, directional strength, etc. Some manufacturing processes can still be improved for better quality. Taking the CFRP tube for example, more layup in the tube manufacturing process can be studied. Careful environmental control in the CFRP material moisture release process can reduce the despace variation in M1 and M2 from the ground to orbit. In summary, composite materials, application in the FORMOSAT-5 RSI structure is successful development.

Acknowledgements Thanks to all AIDC related engineers, their professional workmanship skills produced the RSI structure accurately, quickly and smoothly. Thanks to all CSIST related researchers, successful CFRP tube manufacturing was due to their devotion.

\section{REFERENCES}

ASTM, 2004: Standard Test Method for Moisture Absorption Properties and Equilibrium Conditioning of Polymer Matrix Composite Materials, ASTM D5229 / D5529M-92, ASTM International, West Conshohocken, PA, 2004, doi: 10.1520/D5229_D5229M-92R04.
[Link]

Beller, N. and S. Phofl, 2012: FORMOSAT-5 Top Panel Manufacture Procedure, FS5-STI-TP-003 (NSPO Internal Document).

Chen, C. Y., 2011a: FORMOSAT-5 RSI Manufacturing Validation Final Review Report, FS5RSI-CDRL-4018 (NSPO Internal Document).

Chen, C. Y., 2011b: FORMOSAT-5 RSI Structure Manufacture Final Review Report, FS5RSI-CDRL-4010 (NSPO Internal Document).

Hexcel, 1999: HexWeb ${ }^{\mathrm{TM}}$ Honeycomb Attributes and Properties: A Comprehensive Guide to Standard Hexcel Honeycomb Materials, Configurations, and Mechanical Properties, Hexcel Composite, 40 pp. Available at http://www.hexcel.com/user_area/uploads/Honeycomb_Attributes_and_Properties.pdf.

Hung, H. C., 2010: FORMOSAT-5 RSI Structure Design Report PDR, FS5-RPT-0063 (NSPO Internal Document).

Kuo, J. C., 2009: Technical Specification of FORMOSAT-5 RSI Structure Development Contract., NSPO-RFP0516-A4 (NSPO Internal Document).

Yang, M. Y., 2009: Carbon Fibres and Matrices Databank and Prepared Physical Properties, A023-MEMO-09ME-001 (NSPO Internal Document).

Yang, M. Y., 2013: FORMOSAT-5 RSI Mechanical Stability Computation - Moisture Release Effect, A023MEMO-13-ME-001 (NSPO Internal Document).

Yang, M. Y., 2014: Moisture Desorption and Absorption Properties of Composite Material M55J/954-3 Used in FS5 RSI, A023-MEMO-14-ME-004 (NSPO Internal Document). 